OPEN ACCESS

Edited by:

Zoltán Kónya,

University of Szeged, Hungary

Reviewed by:

Josep Albero,

Instituto de Tecnología Química

(ITQ), Spain

Anita Lloyd Spetz,

Linköping University, Sweden

*Correspondence:

Bilge Saruhan

bilge.saruhan@dlr.de

Specialty section:

This article was submitted to

Translational Materials Science,

a section of the journal

Frontiers in Materials

Received: 07 June 2019 Accepted: 25 September 2019

Published: 10 October 2019

Citation:

Lontio Fomekong $R$ and Saruhan B

(2019) Synthesis of $\mathrm{Co}^{3+}$ Doped

$\mathrm{TiO}_{2}$ by Co-precipitation Route and lts

Gas Sensing Properties.

Front. Mater. 6:252.

doi: 10.3389/fmats.2019.00252

\section{Synthesis of $\mathrm{Co}^{3+}$ Doped $\mathrm{TiO}_{2}$ by Co-precipitation Route and Its Gas Sensing Properties}

\author{
Roussin Lontio Fomekong and Bilge Saruhan* \\ Department of High-Temperature and Functional Coatings, German Aerospace Center (DLR), Institute of Materials Research, \\ Cologne, Germany
}

Undoped and $\mathrm{Co}$-doped $\mathrm{TiO}_{2}$ nanoparticles were synthesized by a facile co-precipitation method and calcined at $700^{\circ} \mathrm{C}$. The phase identification carried out by XRD measurements and Raman spectroscopy analysis of calcined powders reveals the formation of mainly anatase phase for undoped $\mathrm{TiO}_{2}$, and 0.5 mol.\% Co-doped $\mathrm{TiO}_{2}$ whereas rutile phase for $1 \mathrm{~mol} . \% \mathrm{Co}$-doped $\mathrm{TiO}_{2}$. The sensors prepared with these powders deposited on interdigital (IDE) sensor platforms were tested toward $\mathrm{NO}_{2}$ and $\mathrm{H}_{2}$ sensing properties at $600^{\circ} \mathrm{C}$. As the undoped and $0.5 \%$ Co-doped $\mathrm{TiO}_{2}$ reveal n-type behavior, $1 \%$ Co-doped $\mathrm{TiO}_{2}$ shows p-type semi-conductive behavior. One percentage Co-doped $\mathrm{TiO}_{2}$ exhibits good sensing performance toward $\mathrm{NO}_{2}$ while the undoped $\mathrm{TiO}_{2}$ powder yields the best sensor performance toward $\mathrm{H}_{2}$ at $600^{\circ} \mathrm{C}$. This indicates that the crystal structure of $\mathrm{TiO}_{2}$ sensing material must be adjusted depending on the nature of target gas. The results indicate that the main factor influencing high temperature gas sensor performance of nanoparticulate $\mathrm{TiO}_{2}$ is either the alteration of its electronic structure or the type of polymorphs.

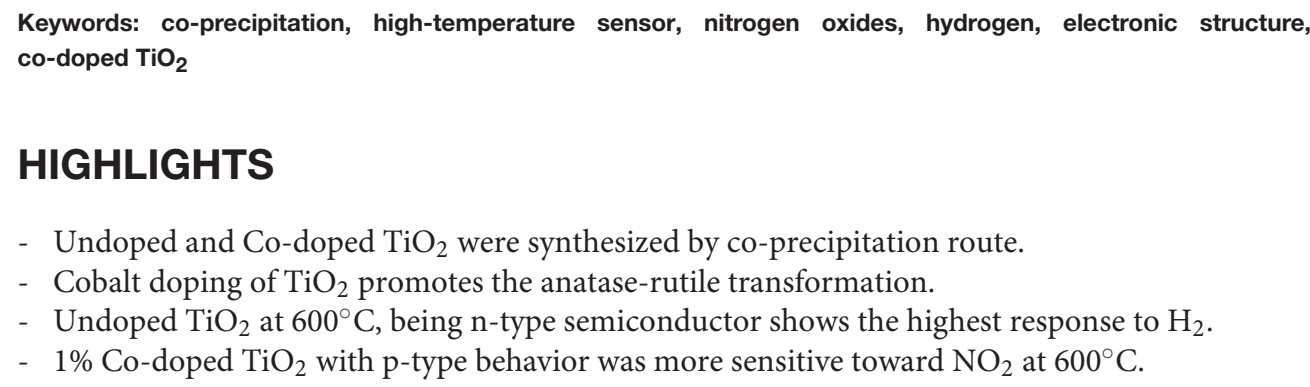

\section{HIGHLIGHTS}

- Undoped and Co-doped $\mathrm{TiO}_{2}$ were synthesized by co-precipitation route.

- Cobalt doping of $\mathrm{TiO}_{2}$ promotes the anatase-rutile transformation.

- Undoped $\mathrm{TiO}_{2}$ at $600^{\circ} \mathrm{C}$, being n-type semiconductor shows the highest response to $\mathrm{H}_{2}$.

- $1 \%$ Co-doped $\mathrm{TiO}_{2}$ with p-type behavior was more sensitive toward $\mathrm{NO}_{2}$ at $600^{\circ} \mathrm{C}$.

\section{INTRODUCTION}

NOx gas sensors are gaining importance in automotive exhausts and combustion systems. Better performance resistive gas sensors can endure the harsh conditions and act effectively despite the strengthened international legislations. The corresponding gas sensors require durability at high working temperatures (exceeding $>>500^{\circ} \mathrm{C}$ ). Semiconducting metal oxides are ideally used as gas sensing materials in resistive sensors due to their numerous benefits such as reasonably high sensitivity, easy fabrication processes and low cost (Dey, 2018). Most of transition metal oxides, such as $\mathrm{SnO}_{2}, \mathrm{WO}_{3}, \mathrm{ZnO}, \mathrm{NiO}$, or $\mathrm{CuO}$ used for this purpose display the optimum sensitivity at temperatures below $400^{\circ} \mathrm{C}$ (Wang et al., 2010). On the other hand, as one of the known 
semiconducting oxides, $\mathrm{TiO}_{2}$ is capable of operating as a gas sensing material at temperatures as high as $600^{\circ} \mathrm{C}$ (Esmaeilzadeh et al., 2012). The additional benefits of $\mathrm{TiO}_{2}$ are non-toxicity, easy fabrication, and the good chemical stability (Chen and Mao, 2007). $\mathrm{TiO}_{2}$ is a high resistive $\mathrm{n}$-type semiconductor with rather poor conductivity to be adopted for sensing oxidative gases such as $\mathrm{NO}_{2}$ (Huusko et al., 1993). Previous studies report that this disadvantage can be overcome by conversion of an n-type oxide to p-type semiconductor through addition of low valence dopant atoms to alter the electronic structure. Some previous studies in our team show how the $\mathrm{Al}$ and $\mathrm{Cr}$-addition alters the electron conductivity of $\mathrm{TiO}_{2}$ from $\mathrm{n}$ - to $\mathrm{p}$-type leading to effective gas sensing materials. As far as Cr-doped $\mathrm{TiO}_{2}$ is concerned, the optimum temperature for sensing properties has been limited with $500^{\circ} \mathrm{C}$ while the $\mathrm{Al}$-doped $\mathrm{TiO}_{2}$ detects $\mathrm{NO}_{2}$ at $600^{\circ} \mathrm{C}$ but the sensitivity is low and the signal converts to p-type at $800^{\circ} \mathrm{C}$ (Saruhan et al., 2013; Gönüllü et al., 2015). Several other papers discuss the relation and reasons between the nature of the electronic structure and the sensing characteristics of the oxide materials (Wisitsoraat et al., 2009; Zhaohui et al., 2013; Gönüllü et al., 2015) and report that the enhancement of the sensing performance can directly be controlled by adjustment of the electronic structure to p-type at the semi-conducting oxide sensing layer.

In order to understand further if such an alteration can be achieved by Co-doping of $\mathrm{TiO}_{2}$ and how this may affect the gas sensing behavior of $\mathrm{TiO}_{2}$, we have synthetized Co-doped $\mathrm{TiO}_{2}$ nanoparticles by oxalate induced coprecipitation method and produced sensors by depositing the powders on interdigital electrodes. The resulting powders are characterized and the sensors are analyzed to identify their $\mathrm{H}_{2}$ and $\mathrm{NO}_{2}$ sensing capabilities. This paper reports, to the best of our knowledge for the first time, the effect of $\mathrm{Co}^{3+}$ doping on the high temperature gas sensing behavior of $\mathrm{TiO}_{2}$.

\section{EXPERIMENTAL}

Undoped and Co-doped $\mathrm{TiO}_{2}$ nanoparticles were synthesized by employing the same processing route. Firstly, the starting precursor solutions were prepared. Cobalt acetate was dissolved in acetic acid as titanium iso-propoxide was diluted separately in absolute ethanol. The cobalt acetate and titanium iso-propoxide solutions were adjusted to obtain 0.5 and $1 \mathrm{~mol} \%$ of cobalt in $\mathrm{TiO}_{2}$ and were labeled as $0.5 \mathrm{Co}$-doped $\mathrm{TiO}_{2}$ and $1 \mathrm{Co}-$ doped $\mathrm{TiO}_{2}$, respectively. These solutions were then mixed to each other and stirred for $5 \mathrm{~min}$. Oxalic acid is utilized for the co-precipitation of a powder from this mixed solution. For that, oxalic acid was dissolved in absolute ethanol solution and poured progressively in to the mixed solution. The resulting mixture was stirred for $1 \mathrm{~h}$ to allow the complete precipitation. The so-obtained precipitate was filtered and dried in oven at $80^{\circ} \mathrm{C}$ yielding a white powder for the undoped and pink colored powder for the Co-doped samples. The as-prepared precursor powder was then calcined for $3 \mathrm{~h}$ at $700^{\circ} \mathrm{C}$ in a muffle furnace under static air.
The XRD diffractograms of the co-precipitated and calcined samples were collected with a D5000 Siemens Kristalloflex O$2 \mathrm{O}$ powder diffractometer having Bragg-Brentano geometry. The reflections from the JCPDS database were assigned to the experimental diffractograms by means of the program EVA from BRUKER AXS.

The Raman spectroscopy measurement were carried out at the Applied University of Bonn-Rhein-Sieg on Senterra Raman spectrometer from Bruker under $532 \mathrm{~nm}$ and $20 \mathrm{~mW}$ by focusing power laser excitation on samples through a $20 \mathrm{x}$ objective. The morphology of the particles was determined by Scanning Electron Microscopy (SEM) analysis using a Zeiss Ultra 55 SEM.

Specific surface area of the samples was determined using Micrometrics Tristar 3,000 equipment using $\mathrm{N}_{2}$ adsorption at $77.150 \mathrm{~K}$. Samples were degassed under vacuum at $120^{\circ} \mathrm{C}$ for $2 \mathrm{~h}$ prior to the surface area measurements. The specific surface area was calculated using the Brunauer-Emmet-Teller (BET) equation.

The as prepared $\mathrm{TiO}_{2}$ and Co-doped $\mathrm{TiO}_{2}$ powders were deposited as thick films using a simple drop-coating method on alumina substrates that were previously fitted with interdigitated electrodes. The sensor measurements were carried out in a specially constructed apparatus consisting of a tube furnace and a custom-built quartz glass reactor providing a thermocouple directed at the specimen. The electrical measurements were performed by using a Keithley 2635A Sourcemeter. The sensor response for $\mathrm{n}$-type semiconductors is defined by $\left(\mathrm{R}_{\text {gas }} / \mathrm{R}_{\text {air }}-1\right) \times 100$ and $\left(\mathrm{R}_{\text {air }} / \mathrm{R}_{\text {gas }}-1\right) \times 100$ for oxidizing and reducing gases, respectively, while for $\mathrm{p}$-type semiconductor, $\left(\mathrm{R}_{\text {gas }} / \mathrm{R}_{\text {air }}-1\right) \times 100$ and $\left(\mathrm{R}_{\text {air }} / \mathrm{R}_{\text {gas }}-1\right) \times 100$ for reducing and oxidizing gases, respectively.

\section{RESULTS AND DISCUSSIONS}

The phase compositions of all synthetized powders were initially investigated by XRD as presented in Figure 1A. The undoped and the $0.5 \mathrm{Co}$-doped $\mathrm{TiO}_{2}$ samples showed pure $\mathrm{TiO}_{2}$ consisted of its two polymorphs; anatase (majority, JCPDS 21-1272) and rutile phases (minority, JCPDS 21-127). No other phase containing Co was observed. The amount of rutile phase was found to be slightly higher in $0.5 \mathrm{Co}$-doped $\mathrm{TiO}_{2}$ than the undoped one. Also, the $1 \mathrm{Co}$-doped $\mathrm{TiO}_{2}$ sample showed only single phase $\mathrm{TiO}_{2}$ but this time the rutile polymorph was the major phase as anatase phase was in trace amount.

The X-ray results indicated that the cobalt dopant promotes the anatase-to-rutile phase conversion of $\mathrm{TiO}_{2}$. As presented on the inset of Figure 1A, a shift of the 2 Theta angles toward the higher values was observed indicating that the lattice parameters of $\mathrm{TiO}_{2}$ decreases on Co-addition since according to the Bragg's law equation $(2 \mathrm{~d} \operatorname{sinO}=\mathrm{n} \lambda)$, the lattice parameter is inversely proportional to $2 \mathrm{O}$. Increasing 2 Theta angle does indeed mean that the lattice parameter decreases. In fact, the ionic radius of $\mathrm{Co}^{3+}$ is smaller than that of $\mathrm{Ti}^{4+}\left(\mathrm{Co}^{3+}=0.685 \AA\right.$, $\mathrm{Ti}^{4+}=0.745 \AA$ ). Hence, this leads to the contraction of the $\mathrm{TiO}_{2}$ unit cell on substitution of $\mathrm{Ti}^{4+}$ through $\mathrm{Co}^{3+}$. If otherwise, the substitution occurs through the incorporation of $\mathrm{Co}^{2+}$, an 


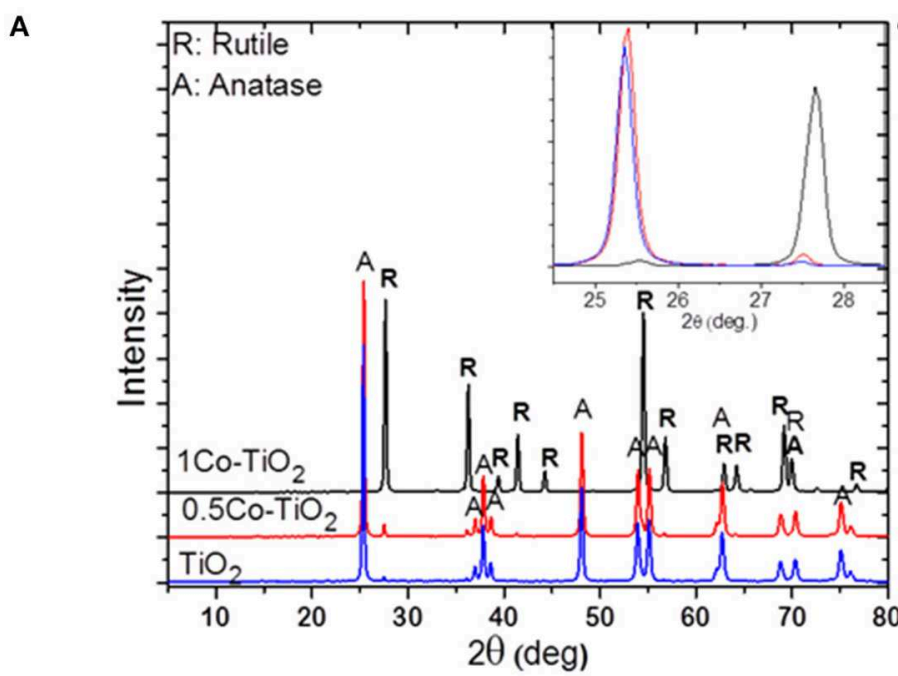

B
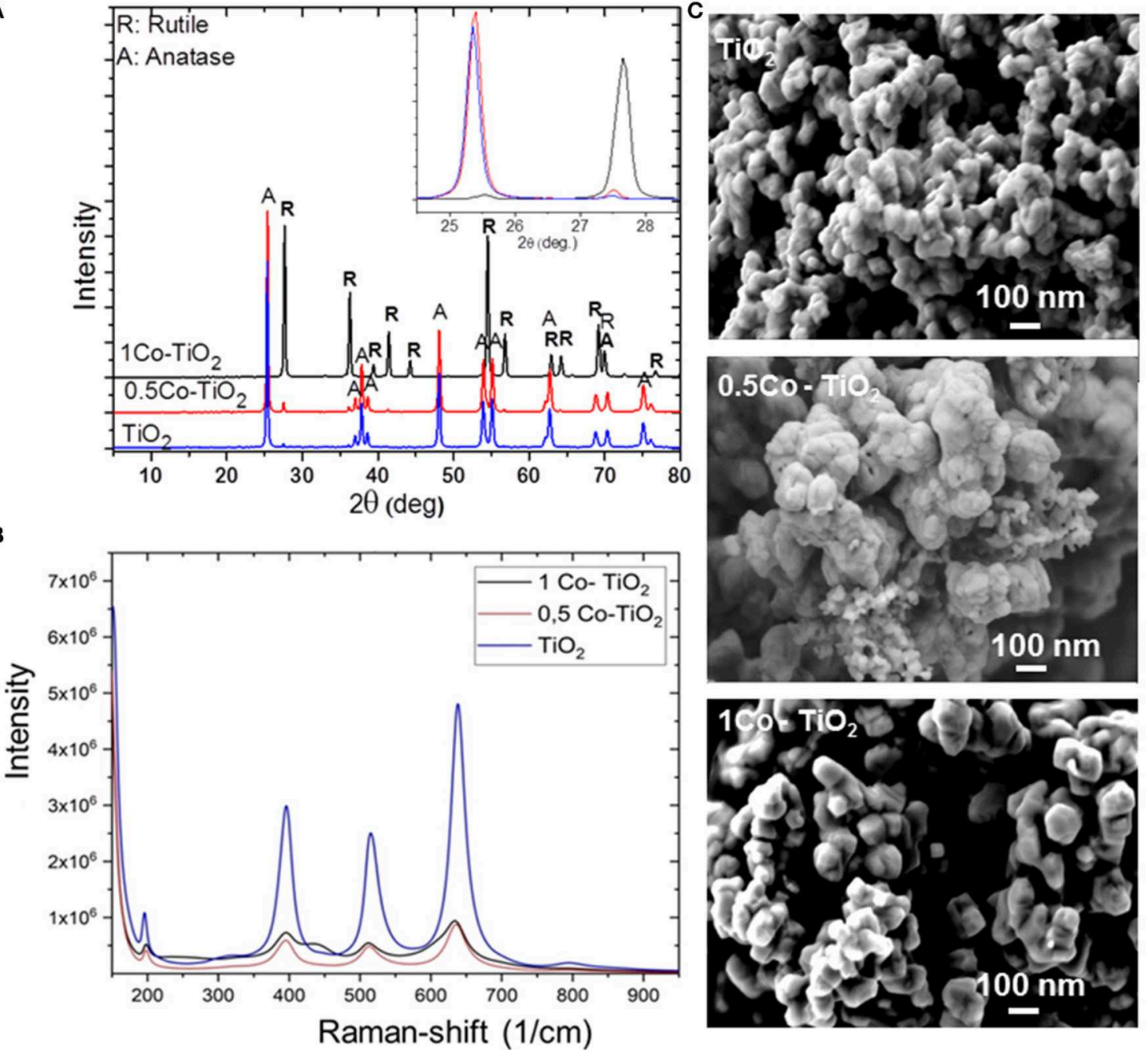

FIGURE 1 | (A) Powder XRD patterns of undoped and Co-doped $\mathrm{TiO}_{2}$, (B) Raman spectra of undoped and Co-doped $\mathrm{TiO}_{2}$, (C) SEM images of undoped and Co-doped $\mathrm{TiO}_{2}$

opposite change in the lattice parameter would be expected (i.e., 2 Theta angles shift to lower values). Since $\mathrm{Co}^{2+}$ has a larger ionic radius $\left(\mathrm{Co}^{2+}=0.79 \AA\right)$ than that of $\mathrm{Ti}^{4+}$, an expansion of the $\mathrm{TiO}_{2}$ unit cell shall occur yielding an increase of the lattice parameters. Chanda et al. has proven this assumption through their structural and magnetic studies on Co-doped $\mathrm{TiO}_{2}$ (Chanda et al., 2018). Thus, it is plausible to consider in the present case that the substitution of $\mathrm{Ti}^{4+}$ sites occurs by smaller ionic radius $\mathrm{Co}^{3+}$ leading to a volume reduction of $\mathrm{TiO}_{2}$-lattice. Therefore, an overall volume contraction of $\sim 8 \%$ is reasonable to obtain through $\mathrm{Co}^{3+}$-doping of $\mathrm{TiO}_{2}$. This promotes the conversion of anatase to rutile because the reconstructive anatase-to-rutile transformation involves a contraction of the c-axis (Hanaor and Sorrell, 2011).

Figure 1B displays the Raman spectra of the samples that were obtained between the wavenumbers of $200-900 \mathrm{~cm}^{-1}$. The Raman lines at $197,390,511,637 \mathrm{~cm}^{-1}$ can be assigned to $\mathrm{E}_{\mathrm{g}}, \mathrm{B} 1_{\mathrm{g}}$,
$\mathrm{A} 1_{\mathrm{g}}$, or $\mathrm{B} 1_{\mathrm{g}}$, and $\mathrm{E}_{\mathrm{g}}$ modes of anatase phase, respectively, which confirm that the phase condition of our Co-doped $\mathrm{TiO}_{2}$ samples belongs to the tetragonal form of anatase phase. Moreover, the spectra show that the peak intensities decrease drastically after doping. As XRD results showed that the main phase for 0.5 Co-doped $\mathrm{TiO}_{2}$ is anatase, the decrease of intensity observed in the Raman spectra can be attributed to the increase of oxygen vacancies which occurred through the substitution of $\mathrm{Ti}^{4+}$ by $\mathrm{Co}^{3+}$ to balance the charge neutrality, relying on the difference between their ionic charges. These vacancies lead to the lattice distortion and results in a change of the diffraction intensity. Similar results were reported by Chanda et al. (2018). On the other hand, the XRD measurement revealed that the sample 1 Co-doped $\mathrm{TiO}_{2}$ contains rutile as the major polymorph as anatase was only present in a very small quantity. This may explain the decrease observed at the Raman spectra of this composition. Moreover, the Raman spectra of $1 \mathrm{Co}$-doped $\mathrm{TiO}_{2}$ 
yielded a smaller shift toward lower wavelengths while new peaks $\left(436 \mathrm{~cm}^{-1}\right)$ appeared indicating the presence of rutile polymorph, as mentioned in literature (Niilisk et al., 2006).

Figure 1C shows the morphology of the synthetized powders. The microscopic investigation revealed the formation of spherical nanoparticles with sizes around $70 \mathrm{~nm}$ that tend to agglomerate at the undoped powder samples. Doping with Co appears to influence the powder morphology. As the sample $0.5 \mathrm{Co}$-doped $\mathrm{TiO}_{2}$ shows more agglomerated spherical particles, the sample 1 Co-doped $\mathrm{TiO}_{2}$ presented larger and well-faceted rhombohedral crystallites with less agglomeration.

The BET-measured specific surface area of the synthetized samples were 8,7 , and $4 \mathrm{~m}^{2} / \mathrm{g}$ for undoped $\mathrm{TiO}_{2}, 0.5 \mathrm{Co}-$ doped $\mathrm{TiO}_{2}$, and $1 \mathrm{Co}$-doped $\mathrm{TiO}_{2}$, respectively. The surface area decreases with the increasing cobalt content, as the greatest decrease being with the $1 \mathrm{Co}$-doped $\mathrm{TiO}_{2}$ that corresponds to the particle size increase as observed by SEM analysis (see Figure 1C).

The sensing properties of the undoped and doped $\mathrm{TiO}_{2}$ were investigated toward $200 \mathrm{ppm} \mathrm{NO} \mathrm{NO}_{2}$ and $200 \mathrm{ppm} \mathrm{H}_{2}$ at $600^{\circ} \mathrm{C}$ using synthetic air as carrier gas. This temperature was chosen on the basis of our previous results obtained with undoped and $\mathrm{Al}$ - and $\mathrm{Cr}$-doped $\mathrm{TiO}_{2}$ relying on the fact that undoped $\mathrm{TiO}_{2}$ is capable of $\mathrm{NO}_{2}$-sensing at above $400^{\circ} \mathrm{C}$ (Saruhan et al., 2013; Gönüllü et al., 2015). In fact, as the temperature increases, the sensor signal and also the response time decreases. Accordingly, our present results indicate that the equilibrium temperature for sensing is at $600^{\circ} \mathrm{C}$. Additionally, it is known that the $\mathrm{TiO}_{2}$ polymorphs will change at temperatures above $700^{\circ} \mathrm{C}$. In order to avoid any temperature-induced complexity related to polymorph and electronic structures and to emphasize the effect of Co-dopant on the sensing properties, the operating temperature has been kept below $700^{\circ} \mathrm{C}$.

As Figure 2A shows, the sensors yield higher response toward $\mathrm{H}_{2}$ than $\mathrm{NO}_{2}$. The $\mathrm{H}_{2}$ sensor responses are 42, 23, and $33 \%$ for undoped, 0.5 Co-doped $\mathrm{TiO}_{2}$ and $1 \mathrm{Co}$-doped $\mathrm{TiO}_{2}$, respectively. The undoped sample shows the highest response toward $\mathrm{H}_{2}$. The presence of Co-dopant seems to decrease the $\mathrm{H}_{2}$-sensing performance of $\mathrm{TiO}_{2}$ even though doping creates more oxygen vacancies in $\mathrm{TiO}_{2}$. This behavior can be attributed to the increase of rutile polymorph content on doping with cobalt, as previously reported, rutile is the less active (in term of functional properties)
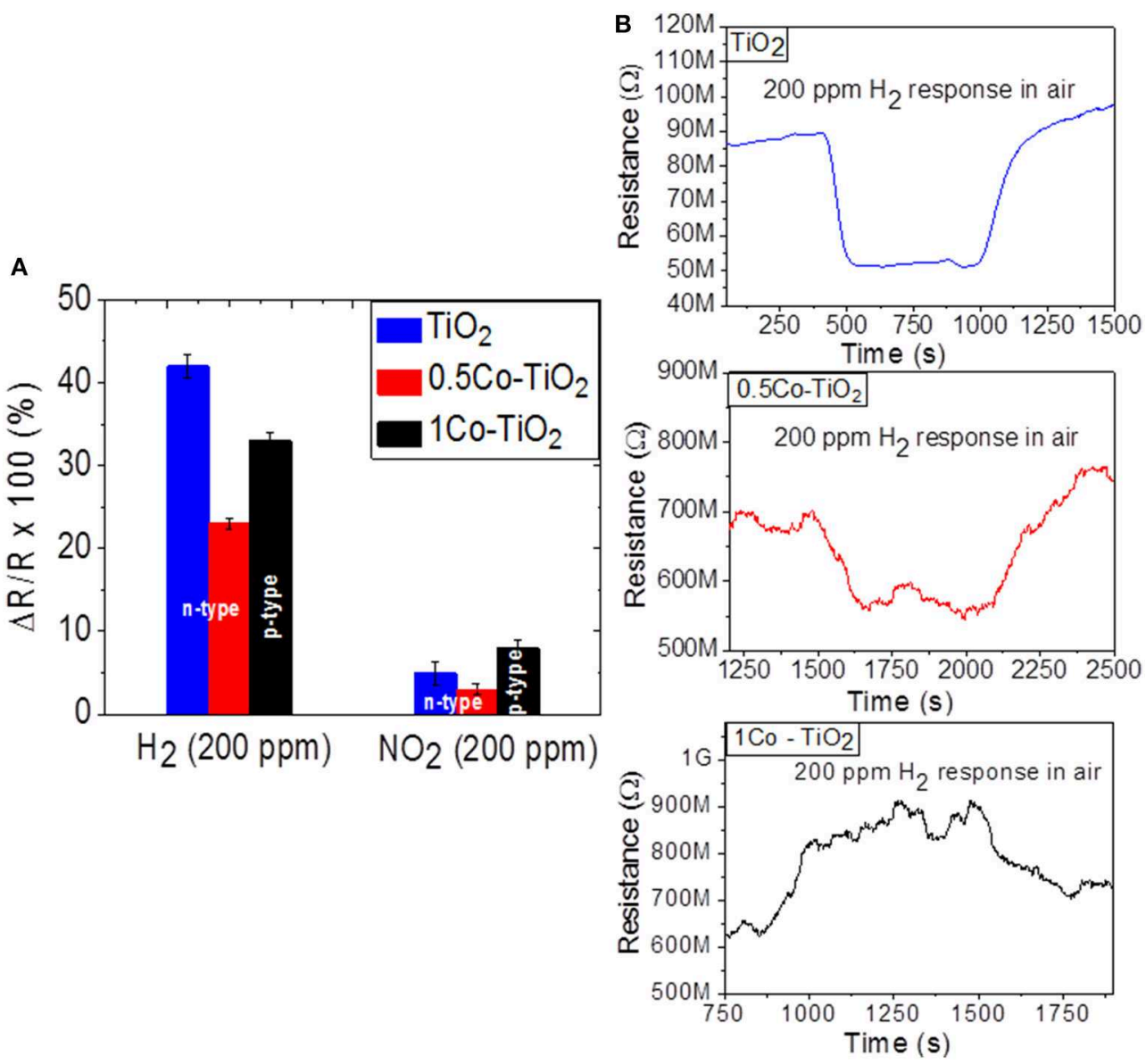

FIGURE 2 | Sensor response of undoped and Co-doped $\mathrm{TiO}_{2}$ toward $\mathbf{( A )} \mathrm{NO}_{2}$ and $\mathrm{H}_{2}$ at $600^{\circ} \mathrm{C}$ and $(\mathbf{B})$ the relevant dynamic responses toward $\mathrm{H}_{2}$. 
polymorph of $\mathrm{TiO}_{2}$ (Luttrell et al., 2014). On the other hand, the 1 Co-doped $\mathrm{TiO}_{2}$ which contains predominantly rutile polymorph showed a higher response toward $\mathrm{H}_{2}$ than 0.5 Co-doped $\mathrm{TiO}_{2}$. This discrepancy can be explained by alteration of the conductivity from $\mathrm{n}$-type to $\mathrm{p}$-type. In fact the dynamic response of the sensors toward $\mathrm{H}_{2}$ given in Figure 2B reveals that undoped and 0.5 Co-doped $\mathrm{TiO}_{2}$ exhibit n-type semi-conductivity (i.e., their electrical resistance decreases upon interaction with hydrogen) while the 1 Co-doped $\mathrm{TiO}_{2}$ yields p-type conductivity (its electrical resistance increases when reducing gas is introduced).

The sensor responses measured toward the oxidizing gas $\mathrm{NO}_{2}$ were 5,3 , and $8 \%$ for undoped, $0.5 \mathrm{Co}$-doped $\mathrm{TiO}_{2}$ and 1 Co-doped $\mathrm{TiO}_{2}$, respectively. In the case of $\mathrm{NO}_{2}$ sensing, the $1 \mathrm{Co}$-doped $\mathrm{TiO}_{2}$ showed the highest response. This may be mainly due to the electronic alteration of $\mathrm{TiO}_{2}$ from $n$ to p-type semiconductor. Previous literature points out that this alteration can be utilized for the detection of oxidizing gas (Huusko et al., 1993). Our current results confirm that the dominant factor for the gas sensing property of the Co-doped $\mathrm{TiO}_{2}$ depend on the existing polymorphs as well as the nature of target gas (oxidizing or reducing). In the case of reducing gases, the type of polymorphs has more influence on the gas sensitivity than the type of electronic structure, while an opposite trend can be observed for oxidizing gases.

Considering these preliminary results, sensing properties of the undoped $\mathrm{TiO}_{2}$ toward $\mathrm{H}_{2}$ and of $1 \mathrm{Co}$-doped $\mathrm{TiO}_{2}$ toward
$\mathrm{NO}_{2}$ are further investigated at $600^{\circ} \mathrm{C}$. Figures $3 \mathrm{~A}, \mathrm{C}$ display the dynamic response of the sensor with undoped $\mathrm{TiO}_{2}$ at $600^{\circ} \mathrm{C}$ to various $\mathrm{H}_{2}$ concentrations $(2,500,5,000$, and $10,000 \mathrm{ppm})$ and those with 1 Co-doped $\mathrm{TiO}_{2}$ to various $\mathrm{NO}_{2}$ concentrations (100, 200 , and $400 \mathrm{ppm}$ ), respectively. As these response measurements exhibit, upon gas exposure, the sensor reaches to an equilibrium resistance value and settles back almost to the original baseline resistance value when the test gas is vented. This sequence has been reproduced for all the applied gas concentrations, demonstrating very good reproducibility and stability at the sensor behavior. For undoped $\mathrm{TiO}_{2}$, the calculated sensor signals were $58 \%$ for $2,500,64 \%$ for 5,000 , and $72 \%$, for $10,000 \mathrm{ppm}$ of $\mathrm{H}_{2}$, while for $1 \mathrm{Co}$-doped $\mathrm{TiO}_{2}$, the sensing signal was $32 \%$ for $100,40 \%$ for 200 , and $55 \%$ for $400 \mathrm{ppm}$ of $\mathrm{NO}_{2}$, respectively. These investigations indicate that the gas response increases with increasing concentration of $\mathrm{NO}_{2}$ suggesting the capability of the sensor for quantitative analysis. In order to confirm the stability and reproducibility of the synthesized undoped $\mathrm{TiO}_{2}$ and $1 \mathrm{Co}-$ doped $\mathrm{TiO}_{2}$ powders at the same $\mathrm{H}_{2}$ and $\mathrm{NO}_{2}$ concentrations, respectively, the sensor tests were repeated by introducing into the test chamber three times $10,000 \mathrm{ppm}_{2}$ (for undoped $\mathrm{TiO}_{2}$ ) and $200 \mathrm{ppm} \mathrm{NO} \mathrm{N}_{2}$ (for 1 Co-doped $\mathrm{TiO}_{2}$ ) under the same test conditions. The dynamic curves of these investigations are shown in Figures 3B,D. The average value of the gas response is $70 \%$ for $\mathrm{H}_{2}$ and $38 \%$ for $\mathrm{NO}_{2}$ for undoped $\mathrm{TiO}_{2}$ and 1 Co-doped $\mathrm{TiO}_{2}$ respectively, with a negligible deviation. Even though the baseline resistance changes slightly with time, the stability of the sensors is maintained well.
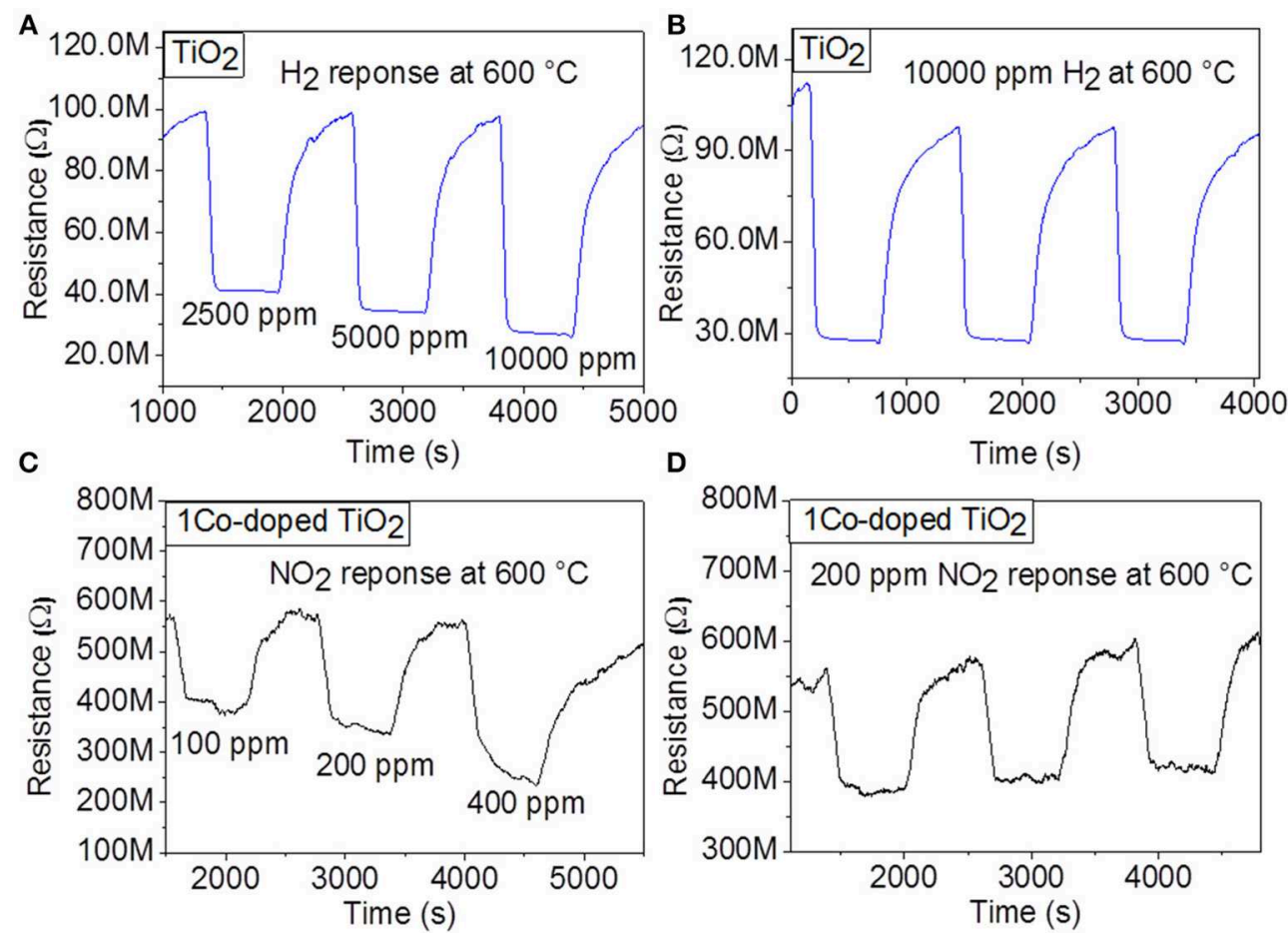

FIGURE 3 | Dynamic response of gas sensors based on $\mathrm{TiO}_{2}$ and 1 Co-doped $\mathrm{TiO}_{2}$ to various concentrations of (A) $\mathrm{H}_{2}$, (C) $\mathrm{NO}_{2}$, respectively, and to (B) 10,000 ppm $\mathrm{H}_{2}$ and (D) $100 \mathrm{ppm} \mathrm{NO}$, respectively at $600^{\circ} \mathrm{C}$. 


\section{CONCLUSION}

This paper reports the successful synthesis of undoped and Co-doped $\mathrm{TiO}_{2}$ nanoparticles by a facile co-precipitation route through the use of oxalic acid. According to the X-ray diffraction and Raman spectroscopy analysis, the substitution of $\mathrm{Ti}^{4+}$ by $\mathrm{Co}^{3+}$ creates oxygen vacancies and promotes the anatase-to-rutile transformation. The sample $1 \mathrm{Co}$-doped $\mathrm{TiO}_{2}$ which reveals p-type conductive behavior yields an enhanced $\mathrm{NO}_{2}$ response at $600^{\circ} \mathrm{C}$ under air as carrier gas. However, the undoped $\mathrm{TiO}_{2}$ shows n-type semiconductor behavior with the highest sensor response toward $\mathrm{H}_{2}$ at $600^{\circ} \mathrm{C}$. The enhancement of high temperature $\mathrm{NO}_{2}$ sensing performance is related to the alteration in electronic structure as well as the formation of rutile polymorph in the 1 Co-doped $\mathrm{TiO}_{2}$ sample. It has been a remarkable effect to obtain two different behaviors by only addition of very small quantities of Co-dopant to $\mathrm{TiO}_{2}$ under the same processing conditions. If the Co-dopant content exceeds $1 \%, \mathrm{CoTiO}_{3}$ starts to form as a secondary phase introducing a new parameter to take into consideration. For the perspective of $\mathrm{NO}_{2}$ sensing

\section{REFERENCES}

Chanda, A., Rout, K., Vasundhara, M., Joshi, S. R., and Singh, J. (2018). Structural and magnetic study of undoped and cobalt doped $\mathrm{TiO}_{2}$ nanoparticles. RSC Adv. 8, 10939-10947. doi: 10.1039/C8RA 00626A

Chen, X., and Mao, S. (2007). Titanium dioxide nanomaterials: synthesis, properties, modifications, and applications. Chem. Rev. 107, 2891-2959. doi: $10.1021 /$ cr0500535

Dey, A. (2018). Semiconductor metal oxide gas sensors: a review. Mater. Sci. Eng. B 229, 206-217. doi: 10.1016/j.mseb.2017.12.036

Esmaeilzadeh, J., Marzbanrad, E., Zamani, C., and Raissi, B. (2012). Fabrication of undoped- $\mathrm{TiO}_{2}$ nanostructure-based $\mathrm{NO}_{2}$ high temperature gas sensor using low frequency AC electrophoretic deposition method. Sens. Actuat. B 161, 401-405. doi: 10.1016/j.snb.2011.10.051

Gönüllü, Y., Haidry, A. A., and Saruhan, B. (2015). Nanotubular Cr-doped TiO2 for use as high-temperature $\mathrm{NO}_{2}$ gas sensor. Sens. Actuat. B 217, 78-87. doi: 10.1016/j.snb.2014.11.065

Hanaor, D. A. H., and Sorrell, C. C. (2011). Review of the anatase to rutile phase transformation. J. Mater. Sci. 46, 855-874. doi: 10.1007/s10853-01 0-5113-0

Huusko, J., Lantto, V., and Torvela, H. (1993). $\mathrm{TiO}_{2}$, thick-film gas sensors and their suitability for NOx monitoring. Sens. Actuat. B 16, 245-248. doi: 10.1016/0925-4005(93)85188-G

Luttrell, T., Halpegamage, S., Tao, J., Kramer, A., Sutter, E., and Batzill, M. (2014). Why is anatase a better photocatalyst than rutile? Model studies on epitaxial $\mathrm{TiO}_{2}$ films. Sci. Rep. 4:4043. doi: 10.1038/srep 04043 optimization, Co-dopant contents between 0.5 and 1 mol.\% may also be considered.

\section{DATA AVAILABILITY STATEMENT}

All datasets generated for this study are included in the manuscript/supplementary files.

\section{AUTHOR CONTRIBUTIONS}

RL has synthesized and characterized the material for sensor application. BS have initiated the idea of applying the Co-dopant to $\mathrm{TiO}_{2}$ and gave Feedback in evaluating the sensing mechanism with this material.

\section{ACKNOWLEDGMENTS}

The authors thank Rene Breuch and Johannes Warmer of H-BRS for Raman Spectroscopy measurements. The grant provided by the DLR-DAAD Fellowship program under no. 284 is acknowledged.

Niilisk, A., Moppel, M., Pärs, M., Sildos, I., Jantson, T., Avarmaa, T., et al. (2006) Structural study of $\mathrm{TiO}_{2}$ thin films by micro-Raman spectroscopy. Cent. Eur. J. Phys. 4, 105-116. doi: 10.1007/s11534-005-0009-3

Saruhan, B., Yüce, A., Gönüllü, Y., and Kelm, K. (2013). Effect of Al doping on $\mathrm{NO}_{2}$ gas sensing of $\mathrm{TiO}_{2}$ at elevated temperatures. Sens. Actuat. B 187, 586-597. doi: 10.1016/j.snb.2013.04.111

Wang, C., Yin, L., Zhang, L., Xiang, D., and Gao, R. (2010). Metal oxide gas sensors: sensitivity and influencing factors. Sensors 10, 2088-2106. doi: $10.3390 / \mathrm{s} 100302088$

Wisitsoraat, A., Tuantranont, A., Comini, E., Sberveglieri, G., and Wlodarski, W. (2009). Characterization of n-type and p-type semiconductor gas sensors based on NiOx doped $\mathrm{TiO}_{2}$ thin films. Thin Solid Films 517, 2775-2780. doi: 10.1016/j.tsf.2008.10.090

Zhaohui, L., Dongyan, D., and Congqin, NLi Z, Ding D, Ning C. (2013). p-type hydrogen sensing with $\mathrm{Al}$ - and $\mathrm{V}$-doped $\mathrm{TiO} 2$ nanostructures. Nanoscale Res. Lett. 8:25. doi: 10.1186/1556-276X-8-25

Conflict of Interest: The authors declare that the research was conducted in the absence of any commercial or financial relationships that could be construed as a potential conflict of interest.

Copyright (c) 2019 Lontio Fomekong and Saruhan. This is an open-access article distributed under the terms of the Creative Commons Attribution License (CC BY). The use, distribution or reproduction in other forums is permitted, provided the original author(s) and the copyright owner(s) are credited and that the original publication in this journal is cited, in accordance with accepted academic practice. No use, distribution or reproduction is permitted which does not comply with these terms. 